\title{
Lectures de Madame de Sévigné. Les lettres de 1671, sous la direction de Cécile Lignereux
}

\section{Antonella Amatuzzi}

\section{(2) OpenEdition}

1 Journals

\section{Edizione digitale}

URL: http://journals.openedition.org/studifrancesi/1136

DOI: 10.4000/studifrancesi. 1136

ISSN: 2421-5856

Editore

Rosenberg \& Sellier

\section{Edizione cartacea}

Data di pubblicazione: 1 novembre 2014

Paginazione: 590-591

ISSN: 0039-2944

\section{Notizia bibliografica digitale}

Antonella Amatuzzi, «Lectures de Madame de Sévigné. Les lettres de 1671, sous la direction de Cécile LignereuX », Studi Francesi [Online], 174 (LVIII | III) | 2014, online dal 01 novembre 2014, consultato il 18 septembre 2020. URL : http://journals.openedition.org/studifrancesi/1136 ; DOI : https://doi.org/ 10.4000/studifrancesi. 1136

Questo documento è stato generato automaticamente il 18 settembre 2020.

\section{(c)}

Studi Francesi è distribuita con Licenza Creative Commons Attribuzione - Non commerciale - Non opere derivate 4.0 Internazionale. 


\title{
Lectures de Madame de Sévigné. Les lettres de 1671, sous la direction de Cécile Lignereux
}

\author{
Antonella Amatuzzi
}

\section{NOTIZIA}

Lectures de Madame de Sévigné. Les lettres de 1671, sous la direction de CÉCILE LIGNEREUX, Presses Universitaires de Rennes, 2012, pp. 232.

1 Questo volume raccoglie studi che si interessano alla dimensione testuale della Correspondance, indagandone le modalità di scrittura e le strategie discorsive svicolandosi deliberatamente da letture critiche che si basano su categorie come classicismo, femminilità o passione materna per spiegarne il valore ma anche da quelle che seguono approcci storici, psicologici o socioletterari.

Questo 'partito preso' innovativo si giustifica con la constatazione che «les lectures textuelles font encore trop souvent figure de parent pauvre des recherches sur l'épistolaire qui privilégient volontiers d'autres angles d'attaque» (p. 7).

3 Un primo gruppo di articoli (Christine Noille, Les lettres de Sévigné sont-elles informes? Éléments pour une rhétorique de la disposition, pp. 19-47; Jean-Yves Vialleton, Écriture épistolaire et rhétorique: Aristote ancêtre de la marquise de Sévigné, pp. 49-66; Cécile Lignereux, Les offres de service à Mme de Grignan. Enquête sur l'acclimatation familière de préconstruits rhétoriques, pp. 67-81) scelgono prospettive prettamente retoriche, soffermandosi sui dispositivi e sulle tecniche discorsive che rendono un determinato effetto di lettura possibile.

4 Altri (Alain Brunn, «Il pleut, nous sommes seuls»: le temps de la lettre, pp. 85-96; Sabine Gruffat, La lettre de provision ou comment «manipuler l'absence», pp. 97-106; Laure Depretto, Autopsie d'un suicide. La mort de Vatel dans la Correspondance, pp. 107-117; Cendrine Pagani-Naudet, Comment lire la lettre de la prairie?, pp. 119-132) affrontano 
questioni poetiche, legate alle scelte estetiche e pragmatiche messe in campo, per esempio, per adattare il 'récit' in funzione del destinatario.

Altri ancora (Chrystelle Barbillon, «Me voilà comme Don Quichotte». Jeux et enjeux des modèles fictionnels romanesques et théâtraux, pp. 135-146; Éric Tourrette, L'ombre des Maximes, pp. 147-158; Constance Cagnat-Deboeuf, «Tous chemins vont à Rome»: le jeu sur les proverbes, pp. 159-173) si interessano alla ricchezza interdiscorsiva della Correspondance dimostrando come l'invenzione epistolare sia indissociabile dal contesto culturale e dalle relazioni intersoggettive e dipenda quindi anche da calcoli pragmatici.

6 Infine alcuni contributi (Stéphane Macé, «Voilà bien des lanternes, ma pauvre bonne». Quelques remarques sur l'emploi des présentatifs voici-voilà, pp. 177-187; Fabienne Boissieras, Regrets, reproches et sentiments de deuil, pp. 189-199; Anne-Marie Garagnon, Étude sylistique d'un fragment de la lettre du 7 juin 1671, pp. 201-218) privilegiano l'analisi stilistica riflettendo sull'effetto di senso provocato da alcuni procedimenti linguistici, che crea un sistema di comunicazione interpersonale originale. 